\title{
Characteristics and implications of podiform- chromite hosted silicate inclusions in the Zedang ophiolite, Southern Tibet
}

GUOLIN GUO ${ }^{12 *}$, WENDY L. MAO ${ }^{2}$, RU Y. ZHANG ${ }^{2}$, JUHN

G. LIOU ${ }^{2}$, W.G. ERNST ${ }^{2}$, XIAODONG LIU ${ }^{1}$, YONG

ZHANG $^{1}, \mathrm{BIN} \mathrm{WU}^{1}$

${ }^{1}$ State Key Laboratory of Nuclear Resources and

Environment, East China University of Technology,

Nanchang 330013, China (*correspondence:

gglrobin@163.com)

2 Department of Geological Sciences, Stanford University, Stanford, CA 94305-2115, U.S.A.

Mineral inclusions in Zedang Chromite

Chromite grains in the Zedang massive chromitite contain in-situ diopside lamellae, octahedral pseudomorphs of serpentine inclusions and other mineral inclusions of diopside, enstatite, hydrous silicates (such as Cr-bearing amphibole and linear serpentine).

\section{Discussion of Results}

Diopside lamellae-bearing chromite probably has a precursor possessing of $\mathrm{CaFe}_{2} \mathrm{O}_{4}$-phase (CF phase) at $>12.5$ $\mathrm{GPa}$ [1]. The individual in-situ octahedral pseudomorphs of serpentine inclusions are considered to be pseudomorphs after isometric ringwoodite [2]. Linear hydrous silicate inclusions implying a fluid infiltration along fracture zones at shallow depths during the period of the last stage

An alternative three-stage model will be used to interpret the formation and evolution of the Zedang chromite. This study on inclusions in chromite also provides a new window to explore the origin and evolution of unusually high-Pressure phase bearing ophiolitic podiform chromitite and mantle dynamics.

\section{Acknowledgements}

This work was financially supported by the National Natural Science Foundation of China (41762005, 41262002) and the research of China Scholarship Council (grant no. 201800880002).

[1] Yamamoto (2009) Lithos 109, 314-322. [2] Griffin (2016) JP 57, 655-684. 